\title{
Feedstock recycling of plastic wastes in cokemaking
}

\author{
M.A. Diez, R Alvarez, S. Melendi and C. Barriocanal \\ Instituto Nacional del Carbón (INCAR), CSIC, Apartado 73, 33080-Oviedo, Spain \\ Email: madiez@incar.csic.es
}

\begin{abstract}
The carbonization of coal to produce metallurgical coke is an alternative route for the feedstock recycling of plastic wastes of different structures and origins. Individual plastics or mixed plastics of domestic origin can be incorporated into typical coking blends as secondary raw materials. The effects of the composition of the plastic wastes on the thermoplastic properties of coal, coking pressure generation and the quality of the cokes produced at a semi-pilot scale are discussed. The plastic wastes studied were chosen because cover a wide spectrum in terms of polymer structure and composition (single and multicomponent wastes) in order to establish the right balance between coking pressure generation and coke quality parameters.
\end{abstract}

\section{Keywords}

Cokemaking, co-processing, plastic wastes

\section{INTRODUCTION}

Alternative plastic waste recycling by methods other than mechanical, chemical and energy recovery processes is of great interest for minimizing environmental damage, especially when waste plastics can be incorporated as a feedstock into existing processes. Processing of the plastic wastes and coprocessing with other organic raw materials by means of pyrolysis under controlled atmosphere could be used for the production of liquid fuels or carbon materials. Recently, integrated steel plants were able to contribute to furthering plastic recycling by the route of the blast furnace and the carbonization process. In 2000, the Nippon Steel Corporation (NSC) began the industrial application of plastic waste recycling in coke ovens at the Nagoya and Kimitsu works with a capacity of 80000 t/year (Kato, 2000; Nomura, 2006). Preliminary data obtained from the use of polyethylene wastes as a minor component in coal blends and, then, carbonized at a semi-industrial scale in the INCAR Coking Test Plant showed that the coal blend used can tolerate up to $3 \mathrm{wt} \%$ of plastic waste without any significant deterioration in the coke quality parameters.

In order to determine the effects of the composition of the plastic waste added to coal blends, this work focuses on: (i) the modification of the thermoplastic properties of a coal blend by plastic waste addition; (ii) on the gas pressure developed during the process; and (iii) on the quality of the metallurgical coke produced.

\section{EXPERIMENTAL}

A typical coal blend used for blast-furnace coke production was used for preparing mixtures with the selected plastic wastes. The main characteristics of this coking blend are: $23.8 \mathrm{wt} \% \mathrm{db}$ volatile matter; $9 \mathrm{wt} \% \mathrm{db}$ ash; $0.65 \mathrm{wt} \% \mathrm{db}$ sulphur; 214 ddpm Gieseler maximum fluidity; and, minus 20 mm Koppers-INCAR contraction. Six mixed plastic wastes provided by the recycling company ABORNASA together with a single multicolour HDPE waste were added as secondary raw materials to the coal blend. The mixed plastics differed in proportion of the six most common 
thermoplastics found in the municipal wastes (Table 1). M5 and M6 result from the blending of M2 with an appropriate amount of multicolour HDPE.

Changes in the plasticity of the coal+plastic mixtures were measured using a R.B. Automazione PL2000 Gieseler plastometer, following the ASTM D2639 standard procedure. The instrument measures the rotation of a stirrer inside a compacted $5 \mathrm{~g}$ sample of particle size $<0.425 \mathrm{~mm}$, while the sample is heated from $300{ }^{\circ} \mathrm{C}$ up to $550{ }^{\circ} \mathrm{C}$ at a heating rate of $3{ }^{\circ} \mathrm{C} / \mathrm{min}$ and the fluidity is recorded in dial divisions per minute (ddpm) as a function of the temperature. For Gieseler fluidity measurements, each plastic waste, cryogenically ground to a particle size of less than $0.4 \mathrm{~mm}$, was physically mixed with the coal blend in amounts of $2 \mathrm{wt} \%$.

The coal blend and its mixtures with the different plastic wastes were carbonised in a semi-pilot moveable-wall oven of $15 \mathrm{~kg}$ of capacity with electrical heating and of the following dimensions: $150 \mathrm{~mm}$ length, $750 \mathrm{~mm}$ height and $250 \mathrm{~mm}$ width. During the carbonisation tests, the temperature of the wall was kept constant at $1010^{\circ} \mathrm{C}$. The coking time was nearly 3 hours, the temperature in the centre of the charge rising to $950^{\circ} \mathrm{C}$. After the hot coke was pushed from the oven, it was quenched with a water spray. The amount of mixed plastic wastes added to the coking blend was 2 wt $\%$. To assess the effect of the different plastic wastes, the coking tests were performed with similar charging (moisture, size distribution, bulk density) and coking conditions. The charge preparation was as close as possible for all the blends (approximately $18 \mathrm{wt} \%$ coal $>3 \mathrm{~mm}$ in size and $70 \mathrm{wt} \%,<2 \mathrm{~mm}$; moisture between $6-8 \mathrm{wt} \%$; and bulk density $785 \pm 30 \mathrm{~kg} / \mathrm{m}^{3} \mathrm{db}$ ). The coking blend without plastic waste addition was taken as a reference and carbonized at three different bulk densities $\left(778,813\right.$ and $\left.835 \mathrm{~kg} / \mathrm{m}^{3} \mathrm{db}\right)$. Bulk density was adjusted by adding water to the coal blend. During the carbonization tests, the temperature evolution at the centre of the charge and the coking pressure exerted on the wall as a function of the carbonization time were monitored. This oven provides enough coke (about $10 \mathrm{~kg}$ ) to enable it to be characterized by standardized procedures. The quality of the resultant cokes with a view to their use in a blast furnace was assessed in terms of their reactivity to $\mathrm{CO}_{2}$ at $1100{ }^{\circ} \mathrm{C}$ for $2 \mathrm{~h}(\mathrm{CRI})$ and the mechanical strength of the partially-gasified coke (CSR) by the NSC method, following the ASTM D5341 standard procedure. In addition, the cold mechanical strength was evaluated on $10 \mathrm{~kg}$ of coke of $>50 \mathrm{~mm}$ initial size employing a JIS drum and rotating it for 150 revolutions. The $\mathrm{DI}^{150}{ }_{15}$ index is defined as the amount of coke $>15 \mathrm{~mm}$, after the mechanical treatment applied (JIS K2151 standard procedure).

\section{RESULTS AND DISCUSSION}

\section{Mixed plastic wastes}

Table 1 shows the composition of the different mixed plastic wastes. They were washed and cut into small laminated pieces of size $<10 \mathrm{~mm}$. It should be noted that generally the separated recycled plastic materials are processed by being granulated or pelletized, melted or partially-melted and extruded to form the end product. However, the mixed plastics selected in this work for feedstock recycling in coke ovens require a minimum of pre-processing in order to reduce the cost of the feedstock.

M1, M3 and M4 are of a very similar composition, the richest wastes in polyolefins being those containing $20 \mathrm{wt} \%$ of PP, nearly $70 \mathrm{wt} \%$ of HDPE. PET, the major non-PE plastic from soft-drink 
bottles in municipal wastes, is another plastic present in these wastes in an amount of $5 \mathrm{wt} \%$. The difference between M3 and M4 is that M3 is an unwashed waste. The remaining mixed plastics contain the six most common thermoplastics from household wastes, polyethylene occurring in two main forms -HDPE and LDPE-, PP, PS, PET and PVC. The only limitation imposed on these wastes was that the PVC must not be higher than $2 \mathrm{wt} \%$ and should preferably be below $1 \mathrm{wt} \%$, to avoid corrosion problems arising from chlorine and hydrogen chlorine present as the light gases. Cellulose which comes from paper labels is another minor component of the waste.

TABLE 1: Composition of the mixed plastic wastes.

\begin{tabular}{|l|c|c|c|c|c|}
\hline & M1 & M2 & M3/M4 & M5 & M6 \\
\hline HDPE & 73.0 & 10.7 & 70.0 & 37.5 & 55.4 \\
\hline LDPE & 0.0 & 5.4 & 0.0 & 3.8 & 2.7 \\
\hline PP & 20.0 & 39.2 & 20.0 & 27.4 & 19.6 \\
\hline PS & 0.0 & 16.6 & 0.0 & 11.6 & 8.3 \\
\hline PET & 5.0 & 18.8 & 5.0 & 13.2 & 9.4 \\
\hline PVC & $<0.1$ & 1.2 & 0.0 & 0.8 & 0.6 \\
\hline Cellulose & 2.0 & 1.2 & $<1.0$ & 0.8 & 0.6 \\
\hline Non-identified & - & 6.9 & - & 4.8 & 3.5 \\
\hline Polyolefins & 93.0 & 55.3 & 90.0 & 68.7 & 77.7 \\
\hline
\end{tabular}

\section{Thermoplastic properties}

Recently, it has been reported that the plastic addition to coal leads to a reduction in the Gieseler maximum fluidity of coking coals, the extent of the reduction depending on the nature and amount of plastic waste added (Díez, 200, 2005; Nomura, 2003; Sakurovs, 2003). Attending to the reduction in fluidity, two different groups of single plastics can be established. Plastics of the first group moderately reduce the fluidity of the coal or coal blends, while those in the second group are strong modifiers of the thermoplastics properties of the coal (Díez, 2000, 2005). The first group includes the three major polyolefins from municipal wastes (HDPE, LDPE and PP) and the second group those polymers such as PS and PET which contain aromatic benzenic rings incorporated into the polymer backbone with and without the presence of heteroatoms.

As a consequence, the Gieseler fluidity of coal will be greatly influenced by the relative proportion of the plastics in mixed wastes. Figure 1 shows the variation of the Gieseler fluidity of blends with the amount of the polyolefins (plastics of type 1) in the waste. It can be observed that the reduction of the Gieseler fluidity is a function of the relative proportion of the plastics classified as type 1 (polyolefins) and type 2 (PS and PET) in the waste. The lower the amount of the polyolefins in the waste, the greater the loss of the fluidity of the blends coal+plastics.

At $2 \mathrm{wt} \%$ addition, no significant changes in the characteristic temperatures of the phenomena occurring in the coal plastic stage (softening, maximum fluidity and resolification, measured by a Gieseler plastometer) were observed. 


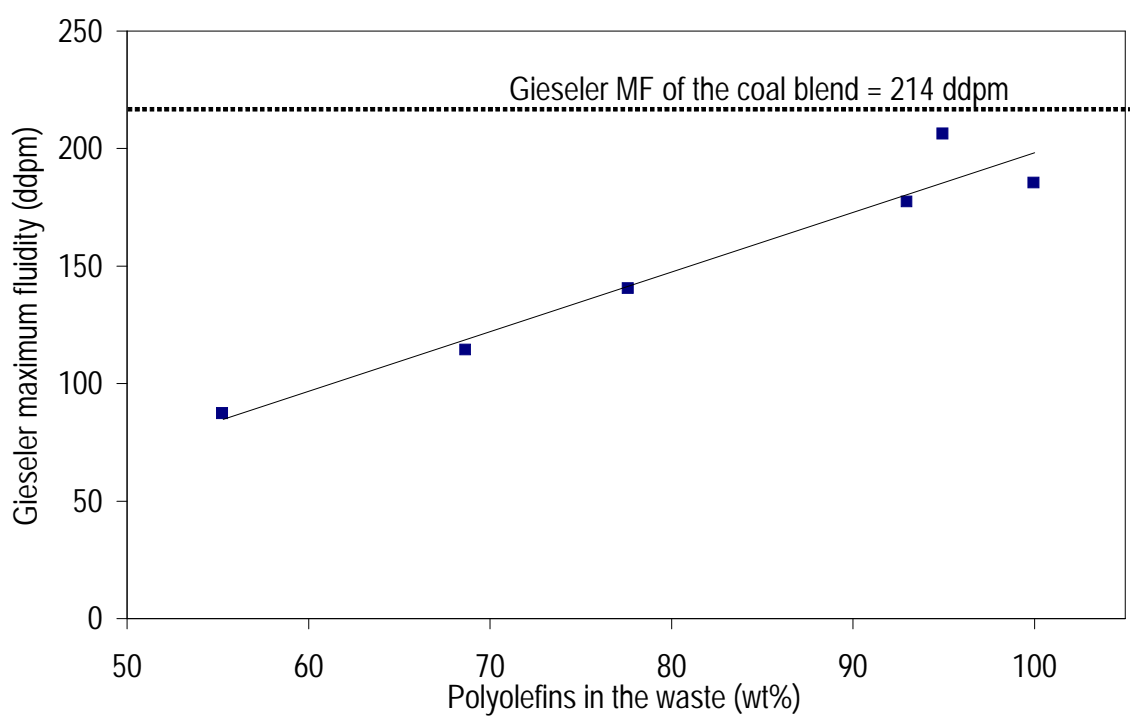

FIGURE 1: Variation of Gieseler fluidity as a function of the amount of polyolefins in the waste.

\section{Coking pressure development}

Mixed plastic waste addition also has a marked effect on the coking pressure generated during carbonization. To avoid secondary effects of an increase in bulk density on coking pressure development, all the carbonization tests were carried out with minor variations in bulk density.

Figure 2 represents the variation of the coking pressure with the composition of the wastes. For comparison purposes, the coking pressure values of the coal blend without the addition of plastics at the three different bulk densities are also represented. As the bulk density increases $(778,813$ and $835 \mathrm{~kg} / \mathrm{m}^{3} \mathrm{db}$ ), the coking pressure increases from 5.5 to $11.8 \mathrm{kPa}$. With $2 \mathrm{wt} \%$ of plastic addition, the coking pressure seems to be clearly dependent on the relative amount of the two polymers groups in the waste which has been defined on the basis of the different Gieseler fluidity reduction.

The single HDPE produces an excessive coking pressure near $50 \mathrm{kPa}$. Taking HDPE as representative of the total polyolefins in each waste, it can be observed that as the amount of HDPE decreases, the coking pressure decreases from $40 \mathrm{kPa}$ to near $13 \mathrm{kPa}$. Consequently, the other polymers such as PET and PS seem to have a beneficial effect on the coking pressure development. When the blend containing the waste M 2 with polyolefins nearly $55 \mathrm{wt} \%$ and PS+PET about 35 $\mathrm{wt} \%$, the coking pressure is considerable reduced. The obtained value of the coking pressure under the coking conditions applied is quite equivalent to that obtained for the coal blend alone ( $13 \mathrm{kPa} v \mathrm{vs}$. $12 \mathrm{kPa}$ for the coal blend).

Three blends lie outside the general trend, giving lower coking pressure values. One of them was carbonized at the lowest bulk density of $758 \mathrm{~kg} / \mathrm{m}^{3} \mathrm{db}$ (M4 waste), another correspond to the unwashed plastic waste M3 which contains biomass (garbage, vegetative materials, etc) and another correspond to the waste M1 waste which contains $2 \mathrm{wt} \%$ cellulose. These results suggest that the presence of such materials as minor components has also a beneficial effect on the coking pressure developed during the process. 

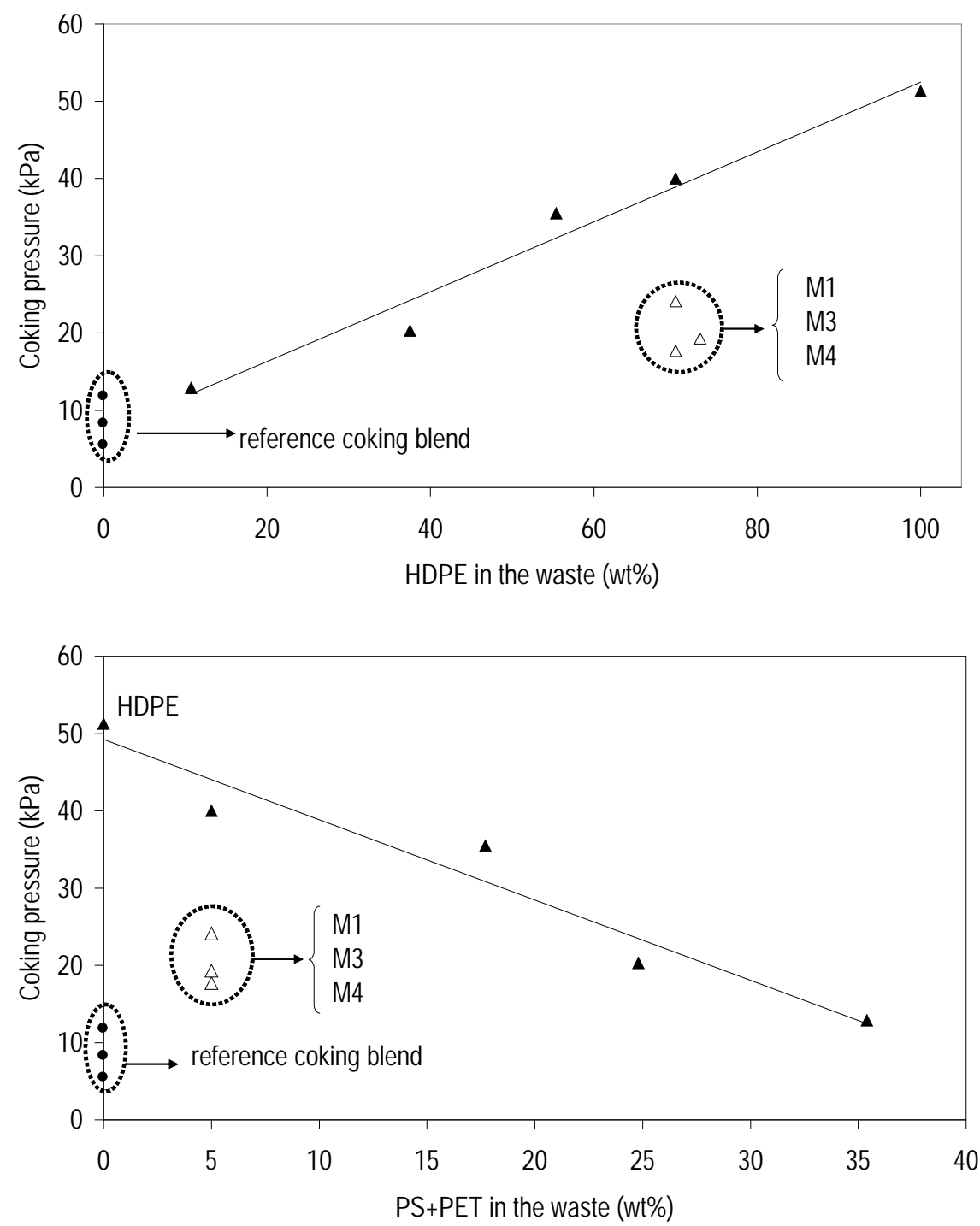

FIGURE 2: Variation of the coking pressure with the composition of the plastic wastes. All co-carbonization tests were carried out at $2 \mathrm{wt} \%$ plastic waste addition to the reference coal blend.

\section{Evaluation of coke quality}

In general, the addition of $2 \mathrm{wt} \%$ plastic waste improves the mechanical strength of the cokes in terms of $\mathrm{DI}^{150}{ }_{15}$ index by 1-4 points. However, no clear relation was found between this coke property and the composition of the wastes.

As regards CRI and CSR, an improvement in CSR caused by the addition of HDPE is confirmed in this series of cokes produced at a semi-pilot scale (Reyes, 2003; Díez, 2007). The HDPE addition keeps the CRI constant, whereas CSR is increased by about 5 points (Figure 3 ). The other wastes increase the CRI as the amount of the plastics of type 2 (PS and PET) increases in the waste. It can be concluded, therefore, that the ratio of the polyolefins to PS+PET is crucial, not only in the development of coking pressure, but also for the mechanical properties of the coke. 


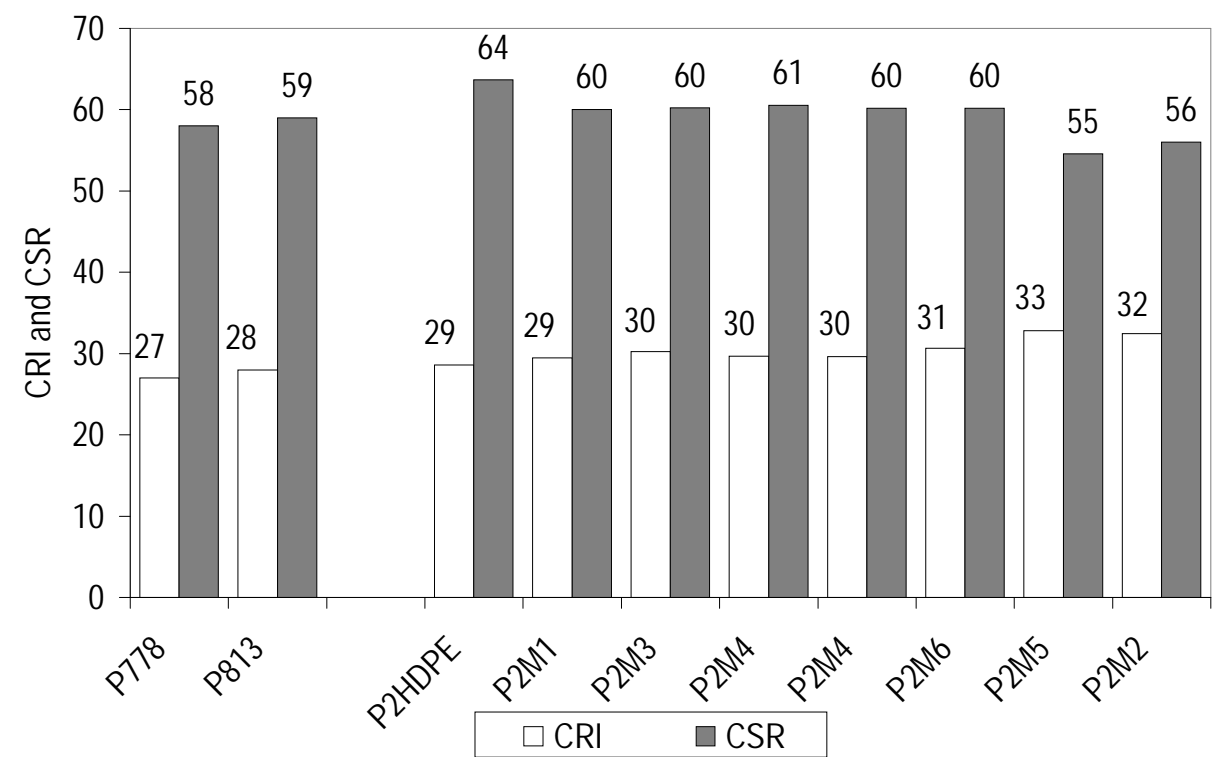

FIGURE 3. Variation of CRI and CSR of semi-pilot cokes from blends containing 2 wt\% of single HDPE and mixed plastic. P778 and P813 denote the reference coal blend carbonized at two different bulk densities (778 and $\left.813 \mathrm{~kg} / \mathrm{m}^{3} \mathrm{db}\right)$.

\section{CONCLUSIONS}

Metallurgical coke manufacture is a valuable alternative of the mixed plastic wastes for feedstock recycling. Key compositional parameters of these feedstocks are direct link to the relative proportion of the polyolefins, the aromatic polymers -PS plus PET- and minor organic materials present in the wastes. To avoid risk of wall damage, the composition of the waste and the bulk density of the charge into the coke oven should be controlled. The best quality coke was obtained by the addition of single HDPE, while coke quality parameters are not greatly affected by the addition of mixed plastic wastes. However, wastes which incorporate plastics and a small amount of organic materials different to polymers have a negative effect on coke quality.

\section{Acknowledgements}

The financial support provided by Spanish Ministry of Education and Science through the research project CTM2004-03254 is gratefully acknowledged. We also thank Abornasa and Arcelor for participating in the project and for providing the post-consumer plastic wastes used for this research and the industrial coal blend. S. Melendi wishes to thank the Government of the Principado de Asturias -Spain- for the award of a predoctoral grant with funds from the "Plan de Investigación, Desarrollo Tecnológico e Innovación de Asturias".

\section{References}

Diez M.A., Alvarez R., Barriocanal C. and Canga C.S. (2000). Modification of coal thermoplastic properties by plastic waste, Eurocarbon 2000, held in Berlín, Germany, 9-13 July 2000. Vol. II: 719-720.

Diez M.A., Barriocanal C. and Alvarez R. (2005). Plastics wastes a modifiers of the thermoplasticity of coal. Energy \& Fuels, 19, 2304-2316.

Diez M.A., Alvarez R., Barriocanal C. and Melendi S. (2007). Possibilities of the coking process for recycling plastic wastes, Eurocoke Summit 2007, Intertech-Pira, held in Nice, France, 16-18 April 2007.

Kato K, Nomura S. and Uematsu H. (2000). Development of waste plastics recycling process using coke ovens. 61st Ironmaking Conference Proceedings, The Iron and Steel Society, 2000; 633-642.

Nomura, S., Kato, K., Nakagawa, T., and Komaki, I. (2003). The effect of plastic addition on coal caking properties during carbonization, Fuel 82, 1775-1782. 
Nomura, S. and Kato, K., (2006). The effect of plastic size on coke quality and coking pressure in the cocarbonization of coal/plastic in coke oven, Fuel 85, 47-56.

Reyes M.A., Kamm M., Canga C.S., Barriocanal C., Álvarez R. and Díez M.A., (2003). Metallurgical coke production as an alternative for plastic waste recycling, Internacional Conference on Carbon, Oviedo, Spain, paper 3.37 (CD-Room format).

Sakurovs, R. (2003). Interactions between coking coals and plastics during co-pyrolysis. Fuel, 82, 1911-1916. 